\title{
1 Population Level Differences in Thermal Sensitivity of Energy Assimilation in Terrestrial \\ 2 Salamanders
}

3

4 Timothy A. Clay ${ }^{1,3}$ and Matthew E. Gifford ${ }^{2}$

5

$6 \quad{ }^{1}$ Corresponding Author, Department of Biology, University of Arkansas at Little Rock, $2801 \mathrm{~S}$.

7 University Ave., Little Rock, Arkansas 72204. taclay@ualr.edu

8

$9 \quad{ }^{2}$ Department of Biology, University of Central Arkansas, 201 Donaghey Ave,Conway, Arkansas 1072035.

11

$12{ }^{3}$ Current Address, Department of Biological Sciences, University of Tulsa, 800 S. Tucker Drive, 13 Tulsa, Oklahoma, 74104

14

15 Running Title: Population level differences of thermal sensitivity

16

17 Keywords: Thermal performance curve; hotter is better; thermal sensitivity; Plethodon 


\section{Abstract}

20 Thermal adaptation predicts that thermal sensitivity of physiological traits should be optimized to

21 thermal conditions most frequently experienced. Furthermore, thermodynamic constraints predict

22 that species with higher thermal optima should have higher performance maxima and narrower

23 performance breadths. Wetested these predictions by examining the thermal sensitivity of energy

24 assimilation between populations within two species of terrestrial-lungless salamanders,

25 Plethodon albagula and P. montanus. Within P. albagula, we examined populationsthat were

26 latitudinallyseparated by $>450 \mathrm{~km}$. Within $P$. montanus, we examined populations that were

27 elevationallyseparated by $>900 \mathrm{~m}$. Thermal sensitivity of energy assimilation varied substantially

28 between populations of $P$. albagula separated latitudinally, but did not vary between populations

29 of $P$. montanus separated elevationally. Specifically, in P. albagula, the lower latitude

30 population had a higher thermal optimum, higher maximal performance, and narrower

31 performance breadth compared to the higher latitude population. Furthermore, across all

32 individuals as thermal optima increased, performance maxima also increased, providing support

33 for the theory that "hotter is better". 


\section{Introduction}

36 Temperature constrains and affects the performance of almost all biological processes. Low

37 temperatures produce slower reaction rates, thus reducing the performance of an organism. As

38 temperature increases, so do the reaction rates of biological processes until performance is

39 maximized, followed by a precipitous drop in performance (Huey and Stevenson 1979;

40 Angilletta 2002; Bulte and Blouin-Demers 2006). Thermal sensitivity of performance is often

41 depicted in the form of a reaction norm or thermal performance curve. From thermal

42 performance curves, researchers often extract three useful performance metrics: the thermal

43 optimum, maximum performance, and the performance breadth (Huey and Stevenson 1979). The

44 thermal optimum is defined asthe temperature at which performance is maximized. Performance

45 breadth is the range of temperatures over which an organism can maintain or exceed some level

46 of performance; in most studies a value of $80 \%$ of maximum performance is used. These metrics

47 and their interrelatedness have produced many models and hypotheses (Huey and Kingsolver

48 1993; Agilletta et al. 2002).

49 Since biological processes are highly dependent on temperature, natural selection should

50 favor individuals that maximize fitness at their most frequent body temperature, whichshould

51 represent a compromise among many performance traits. (Angilletta et al. 2002; Martin and

52 Huey 2008; Gvoždík 2015). This idea has produced a number ofhypotheses concerning body

53 temperature and thermal performance metrics. First, the thermal optimum should be positively

54 correlated with the most frequently experienced body temperature of the organism, and second,

55 the performance breadth should be positively correlated with the magnitude of variation in body

56 temperature experienced (Huey and Stevenson 1979; Hertz et al. 1983; van Berkum 1986).

57 Furthermore, the shape of the performance curve can influence the relationship between thermal 
58 performance breadth and maximal performance due to specialist-generalist trade-offs, with

59 specialization resulting in relatively higher performance with narrower breadths(Huey and Hertz

60 1984).The average body temperature an organism experiences is often the result of a complex

61 interplay between the environment and the costs and benefits of thermoregulation (Huey and

62 Slatkin 1976). Many organisms are relatively inefficient at adjusting their body temperatures and

63 maintain temperatures that are very similar to their environment (Huey 1982). In these

64 "thermoconformers", one would predict that thermal optima would be highly correlated with

65 average operative temperatures, and thermal performance breadth should be correlated with the

66 magnitude of variation in environmental temperatures (Huey and Hertz 1984; Gilchrist 1995).

67 Given the thermodynamic constraints of biological processes, organisms that have

68 thermal optima that are relatively warmer should exhibit a higher level of performance at the

69 optimum temperature compared to those with cooler thermal optima. This idea has led to the

70 theory that "hotter is better" or "warmer is better" (Bennet 1987; Huey and Kingsolver 1989),

71 which suggests that cool adapted species or populations from relatively high latitudes or

72 elevations will perform poorer than those adapted to warmer temperatures at their respective

73 thermal optima (Gillooly et al. 2001). However, organisms may be able to counteract

74 thermodynamic constraints through molecular adaptations, thereby allowing similar maximal

75 performance regardless of their optimal temperature (Hochachka and Somero 2002; Clarke 76 2003).

77 Tests of thermodynamic constraints on the evolution of thermal performance have

78 typically involved species or higher taxa (Angiletta et al. 2010). Such an approach has generally

79 confirmed that warmer thermal optima are correlated with higher maximal performances

80 (Bauwens et al. 1995; Heilmayer et al. 2004; Frazier et al. 2006), but see (Gvoždík and Van 
81 Damme 2008). However, since such comparisons involve species with long evolutionary

82 histories, it is unknown if the observed differences result from thermodynamic or evolutionary

83 constraints. Intraspecific studies of genotypes or populations with differing thermal optima

84 should be compared to explicitly test if thermodynamic constraints are limiting. Previous tests of

85 thermodynamic constraints have produced inconsistent results with some taxa being more

86 evolutionarily conservative with respect to "hotter is better" (Herron 1996; Izem and Kingsolver

87 2005), than others (Wilson 2001; Knies et al. 2009).

We determined geographic variation in thermal sensitivity of energy assimilation in two

89 species of lungless terrestrial salamanders, Plethodon albagula and P. montanus. In both species,

90 small body size, limited movement, and nocturnal nature limit their capacity to thermoregulate,

91 and they are often considered thermoconformers (Olalla-Tarraga 2010). Thus, we expected

92 thermal metrics to be highly correlated to their thermal environments. We chose these two

93 species because of the large environmental gradients that occur within their range; P.albagula

94 occurs over a large latitudinal range $(>450 \mathrm{~km})$ and $P$. montanus occurs over a large elevational

95 range $(>900 \mathrm{~m})$. We chose energy assimilation as a response variable because it is a manifestation

96 of many physiological and behavioral processes and should be more sensitive to temperature

97 than any single constituent process (Angilletta 2001). Furthermore, because of its importance in

98 constraining life history traits, assimilated energy should be under strong selection pressure

99 (Dunham et al. 1989; Blackenhorn et al. 1995). We predicted that populations occurring in

100 cooler climates would have cooler thermal optima, while populations from warmer climates

101 would have warmer thermal optima. We also predicted that populations from environments that

102 were more thermally variable would have larger performance breadths compared to populations

103 from more stable environments. 


\section{Methods}

106 Collection sites were chosen in a manner that would maximize the disparity between mean

107 temperatures. For P. albagula, the southern site was in the Ouachita National Forest within the

108 Interior Highlands of Arkansas (SOUTH; N34.4656, W093.6319, elevation 280m, mean

109 temperature $15.0^{\circ} \mathrm{C}$ ) and the northern site was in the Daniel Boone Conservation Area within

110 the Ozark Highlands of Missouri (NORTH; N38.7589, W91.4065, elevation 270m,mean

111 temperature $12.1^{\circ} \mathrm{C}$ ), a latitudinal separation greater than $450 \mathrm{~km}$. For P. montanus, both

112 populations were collected from the north-facing slope of Mt. Mitchell in North Carolina. The

113 elevational range between the high elevation site (HIGH; N35.7420, W82.2716, elevation

114 1850m,mean temperature $7.5^{\circ} \mathrm{C}$ ) and the low elevation site (LOW; N35.7500, W82.2198,

115 elevation $900 \mathrm{~m}$, mean temperature $10.8^{\circ} \mathrm{C}$ ) was greater than $900 \mathrm{~m}$.

116 We collected 11 P. albagula from the SOUTH site and 9 P. albagula from the NORTH 117 site. We collected 9 P. montanus from the HIGH site and 7 P. montanus from the LOW site.

118 Only adult individuals were used in these experiments. At all stages of this study we followed

119 taxon-specific guidelines approved by the American Society for Ichthyologists and

120 Herpetologists for the care and maintenance of wild animals (Beaupre et al. 2004). We housed

121 salamanders individually in $20 \times 13 \times 5 \mathrm{~cm}$ plastic enclosures lined with moist paper towels; each

122 also contained a crumpled paper towel providing a moist refuge. Prior to testing, salamanders

123 were maintained at $15^{\circ} \mathrm{C}$, a common maintenance temperature for Plethodon studies, for 30 days

124 to minimize stress from capture and allow acclimation to the laboratory (Anthony 1993; Gabor

125 and Jaeger 1995; Mathis et al 2000). 
127 lost:

$$
\text { Assimilated Energy }=E_{a}-E_{f}
$$

128 where $E_{a}$ is energy acquired through foraging and $E_{f}$ is energy lost through feces (Fitzpatrick

129 1972; Angilletta 2001). We quantified energy assimilation using feeding trials (Merchant 1970).

130 We fed salamanders a known quantity of fruit flies (D. hydei), a common food source for lab-

131 based physiological experiments with Plethodon (Crump 1979; Bobka et al. 1981; Feder and

132 Arnold 1982). Each day the number of flies eaten were counted and replaced with fresh flies to

133 the original number. All flies were removed after five days of feeding. At the conclusion of

134 feeding, salamanders were fasted and all feces collected until the digestive tract was clear (3-5

135 days of no feces production). The duration of feces collection was inversely related to

136 temperature, with low temperature requiring up to two weeks from the start of the feeding trial to

137 obtain all feces collected. By subsampling D. hydei and burning them in a bomb calorimeter, we

138 determined the average energy content per fly to be $0.0125 \mathrm{~kJ}$. We multiplied this value by the

139 number of flies consumed over the five days to represent $E_{a}$. We determined that the energy

140 content of feces (via bomb calorimetry) did not differ among temperatures and Plethodon species

141 (species $P=0.1292, \beta=0.61$; temperature $P=0.4364, \beta=0.99$; TA Clay unpublished data) and

142 resulted in a conversion factor of $36.95 \mathrm{~kJ} /$ gram of feces. We multiplied the mass of feces

143 produced by this conversion factor to determine $E_{f}$ for each trial. For each individual, we

144 determined the average daily $E_{a}$ and $E_{f}$ at 5 ecologically relevant temperatures: 5, 10, 15, 20, and

$14525^{\circ} \mathrm{C}$. Prior to thermal performance curve production, energy assimilation was divided by the

146 number of days (5) and the mass of the individual to determine daily assimilation rates per gram

147 of body mass. 
We assumed a critical thermal minimum of $0^{\circ} \mathrm{C}$ for each population and a critical

149 thermal maximum of $33^{\circ} \mathrm{C}$ based on averages from other Plethodon (T.A. Clay unpublished

150 data; Spotila 1972; Layne and Claussen 1982a, b). Statistical procedures and GIS were

151 completed using the statistical platform R version 3.1.2 (R Development Core Team 2014) and

152 packages Ime4, lsmeans, raster, and rgdal (Hijmans and van Ettan 2012; Bates et al. 2015;

153 Bivand et al. 2015; Lenth 2016). For each individual, thermal performance measures were

154 combined with the critical thermal measures and fitted to a range of potential curves using non-

155 linear curve-fitting (Table 1; Angiletta 2006). A best-fit curve was chosen using Akaike

156 Information Criterion corrected (AICc) and from it individual thermal optimum, maximal

157 performance, and performance breadth were estimated. We used ANOVA to test for differences

158 in thermal metrics between populations within species. We used a regression analysis to

159 determine the relationship between thermal optimum and performance maximum. We extracted

160 50-year averages of annual mean temperature (Bio1), and temperature seasonality (Bio4) from

161 the Worldclim dataset for each of our collection sites (Hijmans et al. 2005; Table 2).

\section{Results}

164 A beta-curve provided the best fit for our data (Table 1). Thermal metrics extracted from

165 performance curves differed between northern and southern sites in P. albagula, but did not

166 differ between high and low elevation sites in P. montanus (Table 2, Figs. 1, 2). In P. albagula,

167 the thermal optimum for energy assimilation was higher in the southern population compared to

168 the northern population $\left(P=0.04 ; F_{1,18}=4.84\right.$; Table 2; Fig. 1$)$. Similarly, maximum

169 performance tended to be greater in the southern population compared to the northern population

$170 \quad\left(P=0.05 ; \mathrm{F}_{1,18}=4.25\right.$; Table 2; Fig. 1$)$. Thermal performance breadth was greater in the northern 
171 population compared to the southern population $\left(P=0.04 ; \mathrm{F}_{1,18}=5.02\right.$; Table 2 ; Fig. 1$)$. Thermal

172 optimum $\left(P=0.67 ; \mathrm{F}_{1,14}=0.19\right)$, maximal performance $\left(P=0.08 ; \mathrm{F}_{1,14}=3.62\right)$, and performance

173 breadth $\left(P=0.62 ; \mathrm{F}_{1,14}=0.25\right)$ did not differ between populations of $P$. montanus (Table 2; Fig.

174 2).

To test the hypothesis that "hotter is better”, performance maximum was log transformed

176 and plotted against the inverse of the product of thermal optimum and the Boltzmann Constant.

177 The resulting relationship was negative and significantin $\left(P<0.01 ; \mathrm{R}^{2}=0.55 ; \mathrm{F}_{1,34}=44.52\right.$; Fig.

178 3). A single regression, as opposed to species or population specific regressions, was performed

179 on the relationship because an ANCOVA showed that species and populations did not differ in

180 how maximal performance responded to thermal optimum $(P=0.15)$.

181 Average annual temperature (Bio1) was lower for our low latitude site and low elevation

182 site relative to our high latitude site and high elevation site (Table 2). Temperature seasonality

183 (Bio4) was greater at the high latitude site compared to the low latitude site (Table 2). The

184 magnitude of difference in temperature seasonality between the high and low elevation sites was

185 less and opposite of our expectations (Table 2). Due to the nature of the Worldclim dataset,

186 temperature data from collection sites lack measures of variation, however, these data points

187 represent 50 year averages.

189 Discussion

$190 \quad$ Plethodon montanusfrom the high and low elevation sites showed no differences in

191 thermal sensitivities. Previous studies on ectotherms have found that elevation can produce

192 different thermal sensitivities (van Berkum 1986) even across a narrower elevation range (600m;

193 Navas 1996). However, these studies compared variation among species and the species were 
194 confined to different elevational ranges, thereby increasing the chances for genetic adaptation to 195 the differing thermal environments. Similar to our study, Crowley (1985) found that thermal 196 physiology (thermal optimum) within a lizard species did not differ between elevational sites.

197 Site-specific genetic adaptation to local environmental conditions could be prevented by gene 198 flow between our populations.However, gene flow tends to be limited even across small spatial 199 scales in Plethodon (Cabe et al. 2007) due in part totheir relatively small home ranges 200 (Nishikawa 1990; Marvin 1998) and very short dispersal distances (30-40m; Marsh et al. 2004; 201 Liebgold et al. 2011).

202 The ability to effectively thermoregulate has been shown to influence the thermal optima 203 between species or populations. More effective thermoregulators show fewer differences in 204 thermal optima than those that are less effective (Crowley 1985; van Berkum 1986). The family 205 Plethodontidae are generally thought to bethermoconformers and limited in their opportunities 206 for thermoregulation, suggesting that average environmental temperatures should be highly 207 correlated with their thermal optima. From climatic data, we have shown that average 208 temperatures at both the high and low elevation sites differ in a similar fashion as the two 209 latitudinal sites. Despite the sites having different average annual temperatures, the field body 210 temperatures of salamanders at the elevationally separated sites examined may not be different.

211 If this were the case, it could produce limited selection pressure driving local adaptation. Similar 212 field body temperatures, despite differing annual average temperatures, could arise in

213 salamanders at the elevationally separated populations ifactivity occurs during different times of 214 dayor during different seasons. This would allow the populations to exploit similar temperatures 215 during slightly different parts of the year. Shifted phenologies due to altitudinal gradients are not 216 uncommon and occur in many taxa including Plethodon cinereus (Howard and Wallace 1985; 
217 Petranka 1998; Fielding et al. 1999). Furthermore, the thermal sensitivity of locomotor

218 performance is similar between northern and southern populations of the tree frog Pseudeacris

219 crucifer, and this similarity has been proposed as a reason behind their shifted phenologies

220 (John-Alder 1989). It is unknown if there are different phenologies between the high and low

221 elevation populations of $P$. montanus, but among and within species of Plethodon, activity and

222 abundance appear to be highly dependent on temperature (Petranka 1998; Peterman and

223 Semlitsch. 2013).

224 Optimal temperature for energy assimilation was lower in the higher latitude population,

225 and higher in the lower latitude population of $P$. albagula. This correlates with the cooler

226 temperatures experienced by salamanders at higher latitudes, and warmer temperatures

227 experienced by salamanders at lower latitudes (Table 2). The environmental temperatures and

228 thermal optima, although exhibiting a pattern consistent with thermal adaptation, were dissimilar.

229 This is likely an artifact of our environmental data beingproduced from 50 year averages of

230 weekly average temperatures and not from nightly temperatures during parts of the year when

231 individual salamanders would likely be active. Similar studies comparing latitudinal responses

232 have produced conflicting results, suggesting that some species are inflexible with regard to their

233 thermal sensitivities of physiological traits (John-Adler 1989). However, geographic variation in

234 thermal performance of the marsh frog, Lymnodynastesperonii, suggests that the thermal

235 optimum is correlated with latitude (Wilson 2001). Furthermore, using a common garden

236 experiment, Wilson (2001) suggested that these differences in thermal sensitivities may have a

237 genetic component.

238 Thermal performance breadth was also greater in the high latitude population compared

239 to the low latitude population. The greater performance breadth in the high latitude population of 
240 P. albagulais potentially a response to the increase in temperature seasonality at this site

241 (Stevens 1989). A larger performance breadth would be advantageous for an organism that

242 thermoconforms and experiences a greater range of environmental temperatures (Janzen 1967;

243 Frazier et al. 2006). A narrower performance breadth, as observed in the lower latitude

244 population of P. albagula, could also arise as a side-effect of selection for increased performance

245 (Gilchrist 1995). Generalist-specialist trade-offs predict that an increase in maximal performance

246 can only be possible through the narrowing of performance breadth (Huey and Slatkin 1976;

247 Gilchrist 1995). Alternatively, the narrow performance breadth may be an artifact of assuming

248 the same critical thermal maximum for both populations. We adjusted the critical thermal

249 maximum for each population, increasing it in the southern population and decreasing it in the

250 northern population. Amelioration of differences in thermal performance breadths occurred when

251 the difference between populations in critical thermal maximum differed by three degrees.The

252 likelihood of our populations of $P$. albagula having critical thermal maxima that differ to this

253 extent is unlikely for two reasons. First, within Plethodon, critical thermal maxima differ by less

254 than one degree when acclimated to similar temperatures (Spotila 1972). Second, a sampling of

255 plethodontid salamanders from across the families range exhibit critical thermal maxima that

256 differ by less than three degrees (Spotila 1972).

257 Many aspects of both the organism and the environment can influence the optimal

258 temperature of a physiological trait. If thermal sensitivity is strongly influenced by

259 thermodynamic constraints on underlying biochemical processes, then an increase in optimal

260 temperature should result in an increase in maximal performance; in other words "hotter is

261 better". When plotted on an Arrhenius scale the presence of a thermodynamic constraint should

262 be detectable as a negative relationship between the thermal optimum and maximal performance 
263 with a slope of approximately -0.6, the activation energy, E, of enzymes (Savage et al. 2004).

264 We found strong support for this hypothesis with respect to energy assimilation at the individual

265 level, suggesting that "hotter is better" for energy assimilation. When utilizing this approach with

266 our data, we arrived at a slope of -1.11 , suggesting a high degree of thermodynamic constraint on

267 energy assimilation. This value exceeds the predicted value, and steeper slopes have been

268 observed (-0.97, Frazier et al. 2006; -0.85, Knies et al. 2009) suggesting that hotter is even better.

269 Furthermore, when standardized, our correlation coefficient of -0.97 issimilar to values found in

270 a broad meta-analysis of thermodynamic constraints on physiological and performance traits

271 (correlation coefficients ranged from -0.96 to 0.76, Angillettaet al. 2010).

272 In summary, we tested whether the thermal sensitivity of energy assimilation differed

273 among geographically separated populations of lungless salamanders. We demonstrated

274 intraspecific differences in thermal sensitivity of energy assimilation among populations of $P$.

275 albagulaacross latitude but not among populations of $P$. montanus across elevation,potentially

276 suggesting local adaptation to prevailing environmental conditions in the former case. We cannot

277 definitively rule out the role of developmental plasticity in generating the observed results;

278 however, all salamanders were acclimated to laboratory conditions for 30 days prior to

279 experimentation. These data suggest that geographic proximity between populationsmay limit

280 the amount of local environmental adaptation, although shifts in behavior or differences in trait

281 evolvabilitycould produce similar effects and warrant furtherinvestigation. Furthermore, we

282 found evidence for potential thermodynamic constraints on thermal performance in lungless 283 salamanders.

284

\section{Acknowledgements}


286 We thank J. Chamberlain, W. Peterman, and A. Winters for their help in obtaining individuals

287 from the field and their help with laboratory experiments. We also thank two anonymous

288 reviewers for critical comments that greatly improved this manuscript. This work was carried out

289 under research permit number 12-SC00548 from the North Carolina Wildlife Resources

290 Commission, special use permit number FS-2700-4 from the U.S. Department of Agriculture,

291 and Missouri Wildlife Collector’s Permit \#15203. Financial support was provided by a grant

292 from the U.S. National Science Foundation (DEB-0949038, to M.E.G.) and by the University of

293 Arkansas at Little Rock. The University of Arkansas at Little Rock Institutional Animal Care and

294 Use Committee (IACUC) approved all experimental procedures (protocol: R-09-06)

295 


\section{References}

297 Angilletta, M.J., 2001. Thermal and physiological constraints on energy assimilation in a widespread lizard (Sceloporusundulatus). Ecology. 82, 3044-3056.

299

Angilletta, M.J., 2006. Estimating and comparing thermal performance curves. J. Therm. Biol.

300 31, 541-545.

Angilletta, M.J., Niewiaroski, P.H., Navas, C.A., 2002. The evolution of thermal physiology in 302 ectotherms. J. Therm. Biol. 27, 249-268.

Angilletta, M.J., Huey, R.B., Frazier, M.R., 2010. Thermodynamic effects on organismal performance: is hotter better? Physiol. and Biochem. Zoology. 83, 197-206.

Anthony, C.D., 1993. Recognition of conspecific odors by Plethodon caddoensis and $P$. ouachitae. Copeia. 1993, 1028-1033.

307 Bates, D., Maechler, M., Bolker, B.M., Walker, S. 2015. Fitting linear mixed-effects models using lme4. J. Stat. Software. 67, 1-48.

Beaupre, S.J., Jacobson, E.R., Lillywhite, H.B., Zamudio, K. 2004. Guidelines for use of live amphibians and reptiles in field and laboratory research. American Society of Ichthyologists and Herpetologists.

314 Bauwens, D., Garland Jr, T., Castilla, A.M., Van Damme, R., 1995. Evolution of sprint speed in 315 316 lacertid lizards: morphological, physiological, and behavioral covariation. Evolution. 49, 848-863. 
317 Bennet, A.F., 1987. The accomplishments of ecological physiology, in: Feder, M.E., Bennett, 318 A.F., Burggren, W.W., Huey, R.B., (Eds.), New Directions in Ecological Physiology. 319 Cambridge University Press, New York, pp. 1-8.

320 Bivand, R., Keitt, T., Rowlingson, B., 2015. rgdal: Bindings for the Geospatial Data Abstraction Library. R package version 1.0-4.

322 Blackenhorn, W.U., Preziosi, R.F., Fairbairn, D.J., 1995. Time and energy constraints and the 323 evolution of sexual size dimorphism-to eat or to mate? Evol. Ecol. 7, 369-381.

324 Bobka, M.S., Jaeger, R.S., McNaught, D.C., 1981. Temperature dependent assimilation 325 efficiencies of two species of terrestrial salamanders. Copeia. 1981, 417-421.

326 Bulté, G., Blouin-Demers, G., 2006. Cautionary notes on the descriptive analysis of performance $327 \quad$ curves in reptiles. J. Ther. Biol. 31, 287-291.

328 Cabe, P.R., Page, R.B., Hanlon, T.J., Aldrich, M.E., Connors, L., Marsh, D.M., 2007. Fine-scale 329 population differentiation and gene flow in a terrestrial salamander (Plethodon cinereus)

331 Clarke, A., 2003. Costs and consequences of evolutionary temperature adaptation. TRENDS $332 \quad$ Ecol. Evol. 18, 573-581.

333 Crowley, S.R., 1985. Thermal sensitivity of sprint-running in the lizard Sceloporusundulatus: 334 support for a conservative view of thermal physiology. Oecologia. 66, 219-225.

335 Crump, M.L., 1979. Intra-population variability in energy parameters of the salamander 336

337 Dunham, A.E., Grant, B.W., Overall, K.L., 1989. The interface between biophysical ecology and 338 the population ecology of terrestrial vertebrate ectotherms. Physiol. Zool. 62, 335-355. 
339 Feder, M.E., Arnold, S.J., 1982. Anaerobic metabolism and behavior during predatory encounters between snakes (Thamnophis elegans) and salamanders (Plethodon jordani). Oecologia. 53, 93-97.

342 Fielding, C.A., Whittaker, J.B., Butterfield, J.E.L., Coulson, J.C., 1999. Predicting responses to climate change: the effect of altitude and latitude on the phenology of the Spittlebug Neophilaenuslineatus. Funct. Ecol. 13, 65-73.

Fitzpatrick, L.C., 1972. Energy allocation in the Allegheny Mountain salamander, Desmognathusochrophaeus. Ecol. Monogr. 43, 43-48.

347 Frazier, M.R., Huey, R.B., Berrigan, D., 2006. Thermodynamics constrain the evolution of insect population growth rates: “warmer is better”. Am. Nat. 168, 512-520.

349 Gabor, C.R., Jaeger, R.G., 1995. Resource quality affects the agnostic behavior of territorial salamanders. Anim. Behav.49, 71-79.

351 Gilchrist, G.W., 1995. Specialists and generalists in changing environments. 1. Fitness landscapes of thermal sensitivity. Am. Nat. 146, 252-270.

353 Gillooly, J.F., Brown J.H., West, G.B., Savage, V.M., Charnov, E.L., 2001. Effects of size and 354 temperature on metabolic rate. Science. 293, 2248-2251.

355 Gvoždík, L., 2015. Mismatch between ectotherm thermal preferenda and optima for swimming: 356 a test of the evolutionary pace hypothesis. Evol. Biol 42, 137.

357 Gvoždík, L, Van Damme, R., 2008. The evolution of thermal performance curves in semi358 359 aquatic newts: Thermal specialists on land and thermal generalists in water? J. Therm. Biol. 7, 395-403. 
360

361

362

363

364

365

366

367

368

369

370

371

372

373

374

375

376

377

378

379

380

381

Heilmayer, O., Brey, T., Portner, H.O., 2004. Growth efficiency and temperature in scallops: a comparative analysis of species adapted to different temperatures. Funct. Ecol. 18, 641647.

Herron, J. 1996. Genetic variation, thermal sensitivity, and thermal acclimation in Volvox aureus and Volvoxglobator. PhD diss. University of Washington, Seattle.

Hertz, P.E., Huey, R.B., Nevo, E., 1983. Homage to Santa Anita: thermal sensitivity of sprint speed in agamid lizards. Evolution. 37, 1075-1084.

Hijmans, R.J., Cameron, S.E., Parra, J.L., Jones, P.G., Jarvis, A., 2005. Very high resolution interpolated climate surfaces for global land areas. Int. J. Climatol. 25, 1965-1978.

Hijmans, R.J., van Ettan, J., 2012. raster: Geographic analysis and modeling with raster data. R package version 2.0-12.

Hochachka, P.W., Somero, G.N., 2002. Biochemical adaptation: mechanism and process in physiological evolution. Academic Press, New York.

Howard, J.H., Wallace, R.L., 1985. Life history characteristics of populations of the long-toed salamander (Ambystomamacrodactylum) from different altitudes. Am. Midl. Nat. 113, $361-373$.

Huey, R.B., 1982. Temperature, physiology, and the ecology of reptiles, in: Gans, C., Pough, F.H., (Eds.), Biology of the Reptilia, Vol. 12., Academic Press, New York.

Huey, R.B., Hertz, P.E., 1984. Is a jack-of-all temperatures a master of none? Evolution. 38, $441-444$.

Huey, R.B., Kingsolver, J.G., 1989. Evolution of thermal sensitivity of ectotherm performance. TRENDS Ecol. Evol. 4, 131-135. 
382 Huey, R.B., Kingsolver, J.G., 1993. Evolution of resistance to high temperature in ecotherms. Am. Nat. 142, s21-s46.

Huey, R.B., Slatkin M., 1976. Cost and benefits of lizard thermoregulation. The Q. Rev. Biol. 51, 363-384.

Huey, R.B., Stevenson, R.D., 1979. Integrating thermal physiology and ecology of ectotherms: a discussion of approaches. Am. Zool. 19, 357-366.

Izem, R., J. G. Kingsolver. 2005. Variation in continuous reaction norms: quantifying directions of biological interest. Am. Nat. 166, 277-289.

Janzen, D.H., 1967. Why mountain passes are higher in the tropics. Am. Nat. 101, 233-249.

391 John-Alder, H.B., Barnhart, M.C., Bennett, A.F., 1989. Thermal sensitivity of swimming performance and muscle contractions in northern and southern populations of tree frogs (Hyla crucifer). J. Exp. Biol. 142, 357-372.

394 Layne, J.R., Claussen, D.L., 1982a. Seasonal variation in the thermal acclimation of critical thermal maxima (CTMax) and minima (CTMin) in the salamander Euryceabislineata. J. Therm. Biol. 7, 28-33.

397 Layne, J.R., Claussen, D.L., 1982b. The time courses of CTmax and CTmin acclimation in the 398 salamander Desmognathusfuscus. J. Therm. Biol. 7, 139-141.

399 Lenth, R.V. 2016. Least-square means: the $\{$ R $\}$ package $\{$ lsmeans $\}$. J. Stat. Software. 69, 1-33.

400 Liebgold, E.B., Brodie III, E.D., Cabe, P.A., 2011. Female philopatry and male-biased in a 401 direct-developing salamander, Plethodon cinereus. Mol. Ecol. 20, 249-257.

402 Marsh, D.M., Thakur, K.A., Bulka, K.C., Clarke, L.B., 2004. Dispersal and colonization through 403 open fields by a terrestrial, woodland salamander. Ecology. 85, 3396-3405. 
404 Martin, T.L., Huey, R.B., 2008. Why “suboptimal is optimal: Jensen’s inequality and ectotherm 405 preferences. Am. Nat. 171, E102-18.

406 Marvin, G.A., 1998. Interspecific aggression and spatial relationships in the salamanders

407 Plethdonkentucki and Plethodon glutinosus: evidence of interspecific competition. Can. J. $408 \quad$ Zool. 76, 94-103.

409 Mathis, A., Schmidt, D., Medleu, K., 2000. The influence of residency status on agnostic 410 behavior of male and female Ozark zigzag salamandersPlethodon angusticlavius. Am. 411 Midl. Nat. 143, 245-249.

412 Merchant, H.J., 1970. Estimated energy budget of the red-backed salamander, Plethodon 413 cinereus. PhD Diss. Rutgers University, New Jersey.

414 Navas, C.A., 1996. Metabolic physiology, locomotor performance, and thermal niche breadth in 415 Neotropical anurans. Physiol. Zool. 69, 1481-1501.

416 Nishikawa, K.C., 1990. Intraspecific spatial relationships of two species of terrestrial 417 salamanders. Copeia. 1990, 418-426.

418 Olalla-Tárraga, M.Á., Bini, L.M., Diniz-Filho, J.A.F., Rodríguez, M.Á., 2010. Cross-species and 419 assemblage-based approaches to Bergmann's rule and the biogeography of body size in $420 \quad$ Plethodon salamanders of eastern North America. Ecography. 33, 362-368.

421 Peterman, W.E., Semlitsch, R.D., 2013. Fine-scale habitat associations of a terrestrial 422 salamander: the role of environmental gradients and implications for population 423 dynamics. PLOS ONE. 8, e62184.

424 Petranka, J.W., 1998. Salamanders of the United States and Canada. Smithsonian Institution 425 Press, Washington D.C. 
426 R Development Core Team, 2011. R: a language and environment for statistical computing.

427 Vienna, Austria: R Foundation for Statistical Computing. Available online at: URL $428 \quad$ https://www.r-project.org

429 Savage V.M., J.F. Gillooly, J.H. Brown, G.B. West, and E.L. Charnov. 2004. Effects of body $430 \quad$ size and temperature on population growth. Am Nat 163:429-441

431 Spotila, J.R., 1972. Role of temperature and water in the ecology of lungless salamanders. Ecol. $432 \quad$ Monogr. 42, 95-125.

433 Stevens, G.C., 1989. The latitudinal gradient in geographical range: how so many species coexist 434 in the tropics. Am. Nat. 13, 3240-3256.

435 van Berkum, F.H., 1986. Evolutionary patterns of the thermal sensitivity of sprint speed in $436 \quad$ Anolis lizards. Evolution. 40, 594-604.

437 Wilson, R.S., 2001. Geographic variation in thermal sensitivity of jumping performance in the 438 frog Limnodynastesperonii. J. Exp. Biol. 204, 4227-4236. 
440 Table 1. Models and AICc scores used for the thermal performance curve selection for each

441 species.

\begin{tabular}{|c|c|c|c|}
\hline Model & Formula & P. albagula & P. montanus \\
\hline Beta & $\mathrm{Y}=\mathrm{a}^{*}\left(((\mathrm{~b}-\mathrm{X}) /(\mathrm{b}-\mathrm{c}))^{*}(\mathrm{X} / \mathrm{c})^{\wedge}(\mathrm{c} /(\mathrm{b}-\mathrm{c}))\right)$ & -16.2 & -15.6 \\
\hline Polynomial & $\mathbf{Y}=\mathbf{a}+\mathbf{b}^{*} \mathbf{X}+\mathbf{c}^{*} \mathbf{X}^{\wedge} \mathbf{5}$ & -14.5 & -14.0 \\
\hline Gaussian & $Y=a^{*} \exp \left(-0.5^{*}((\operatorname{abs}(X-b)) / c)^{\wedge} 2\right.$ & -12.4 & -15.1 \\
\hline Quadratic & $\mathbf{Y}=\mathbf{a}^{*} \mathbf{X}^{\wedge} \mathbf{2}+\mathbf{b}^{*} \mathbf{X}+\mathbf{c}$ & -10.8 & -9.8 \\
\hline
\end{tabular}

442

443

444

445

446

447

448

449

450

451

452

453

454

455

456

457

458

459

460 
461 Table 2. Average and standard deviation for thermal optimum ( $\left.T_{o p t}\right)$, maximal performance

$462\left(P_{\max }\right)$, and performance breadth $\left(B_{80}\right)$ for two populations of each species. 50-year average of

463 annual mean temperature (mean of all weekly mean temperatures; Bio1), and temperature

464 seasonality (standard deviation of the weekly mean temperatures multiplied by 100; Bio4).

465 Temperature data was obtained from the WorldClim data set (Hijmans et al. 2005).

\begin{tabular}{lllllll}
\hline Species & Population & $T_{\text {opt }}$ & $P_{\max }$ & $B_{80}$ & Bio1 & Bio4 \\
\hline P. albagula & NORTH & $21.7 \pm 2.2$ & $\mathbf{0 . 0 9} \pm \mathbf{0 . 0 3}$ & $\mathbf{1 1 . 5} \pm \mathbf{1 . 6}$ & $\mathbf{1 2 . 1}$ & $\mathbf{9 3 5 . 0}$ \\
& SOUTH & $24.8 \pm \mathbf{1 . 9}$ & $\mathbf{0 . 1 3} \pm \mathbf{0 . 0 5}$ & $\mathbf{9 . 0} \pm \mathbf{1 . 6}$ & $\mathbf{1 5 . 0}$ & $\mathbf{7 9 7 . 7}$ \\
P. montanus & HIGH & $22.8 \pm \mathbf{1 . 0}$ & $\mathbf{0 . 1 0} \pm \mathbf{0 . 0 2}$ & $\mathbf{1 0 . 7} \pm \mathbf{0 . 7}$ & $\mathbf{7 . 5}$ & $\mathbf{6 8 9 . 8}$ \\
& LOW & $22.6 \pm \mathbf{1 . 9}$ & $\mathbf{0 . 1 3} \pm \mathbf{0 . 0 4}$ & $\mathbf{1 0 . 9} \pm \mathbf{1 . 3}$ & $\mathbf{1 0 . 8}$ & $\mathbf{6 9 5 . 8}$ \\
\hline
\end{tabular}

466

467

468

469

470

471

472

473

474

475

476

477

478

479

480

481 
482 Figure 1. Estimated population level thermal performance curves of energy assimilation for

483 southern (solid line, solid circles) and northern (dashed line, open circles) latitude populations of

484 P. albagula. Light shaded region indicates performance breadth range and dark shaded region

485 indicates overlap in performance breadth ranges between populations. Vertical lines represent

486 thermal optimum for each population.

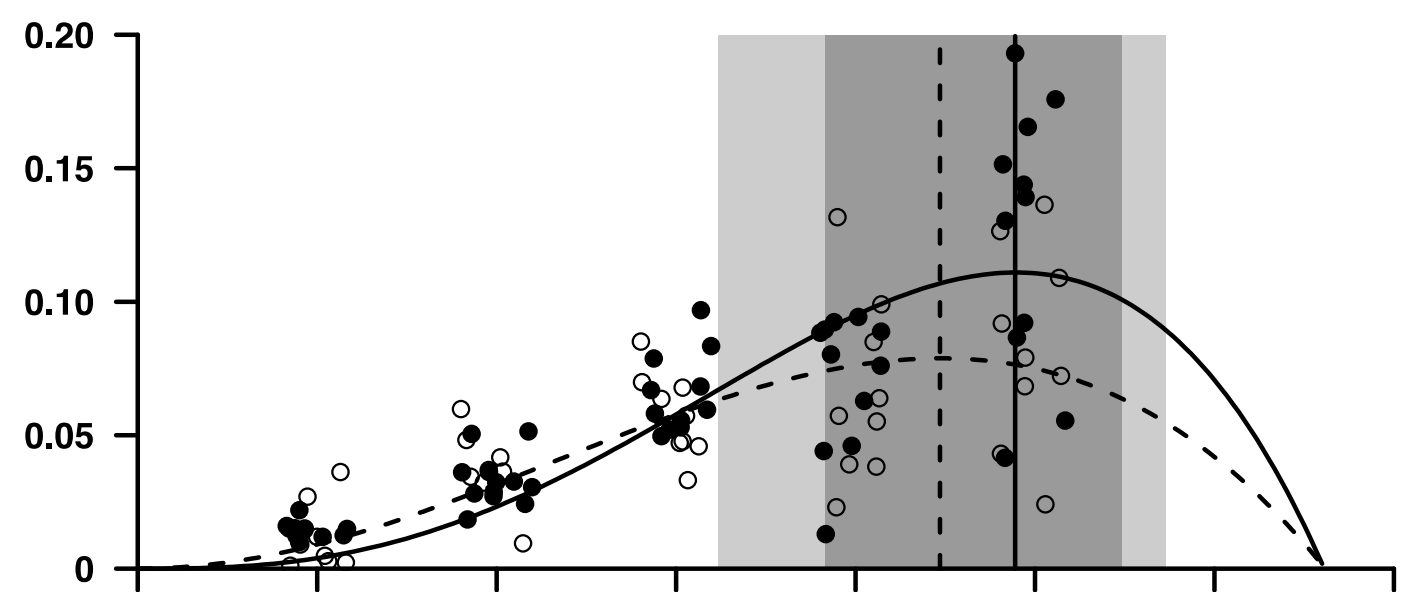


496 Figure 2. Estimated population level thermal performance curves of energy assimilation for low

497 (solid line, solid circles) and high (dashed line, open circles) elevation populations of $P$.

498 montanus.Light shaded region indicates performance breadth range and dark shaded region

499 indicates overlap in performance breadth ranges between populations. Vertical lines represent

500 thermal optimum for each population.

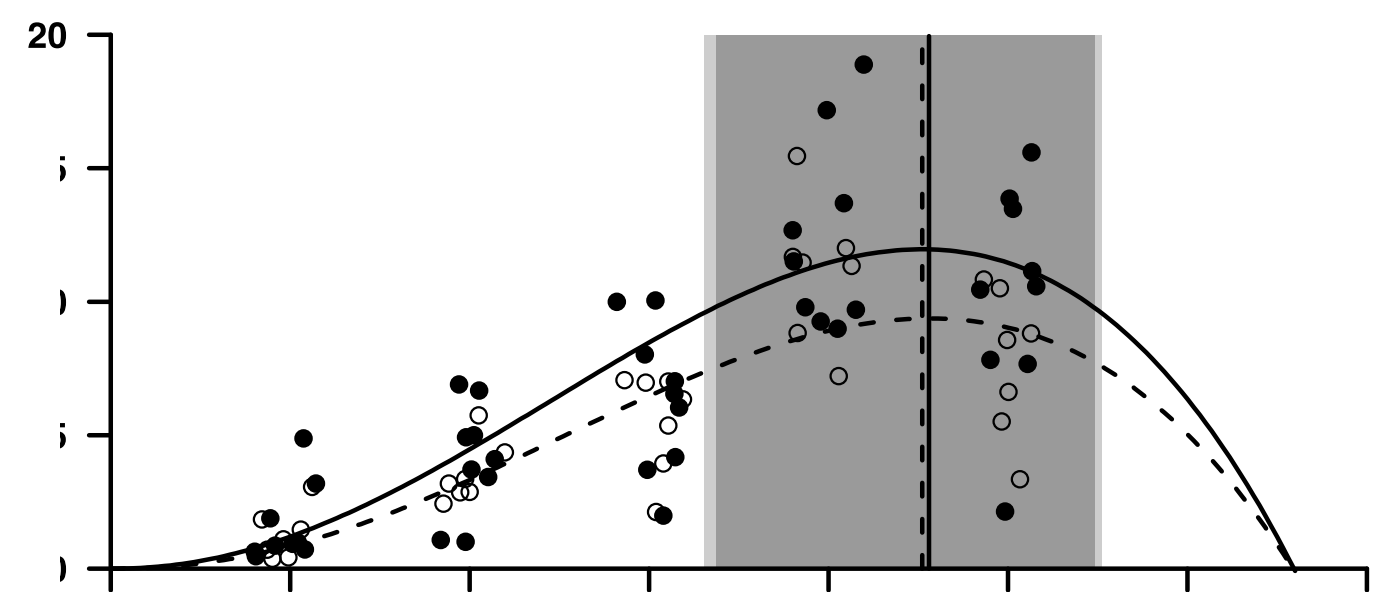

501

502

503

504

505

506

507

508 
509 Figure 3. Arrhenius plot of maximal performance (natural log) against the thermal

510 optimum(expressed on an Arrhenius scale, $1 / \mathrm{K} *$ Thermal optimum) for $P$. albagula (solid circles)

511 and P. montanus (open circles). Regression line (solid line) represents a best-fit line for all

512 individuals. Dashed lines represent 95\% confidence intervals.

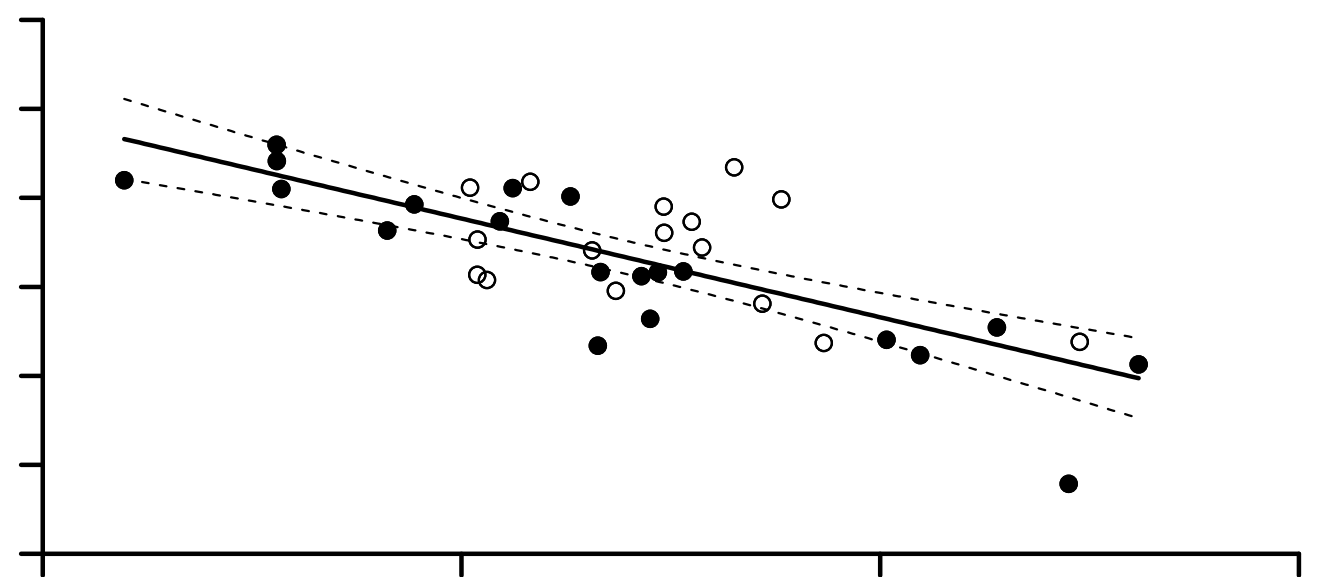




\section{Vitae}

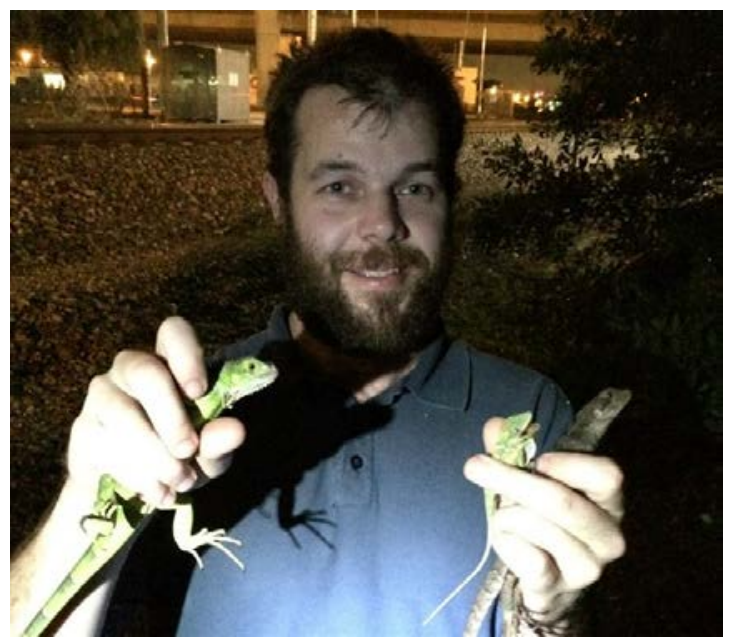

517 Timothy A. Clay is a Post-doc in the Department of Biological Sciences at the University of

518 Tulsa. Tim received his B.S. in Biology from the University of Maryland, Baltimore County, his

519 M.S. in Marine Biology from Nicholls State University, and his Ph.D. in Applied Biosciences at 520 the University of Arkansas at Little Rock. His research focuses on the behavior and physiology

521 of reptiles and amphibians.

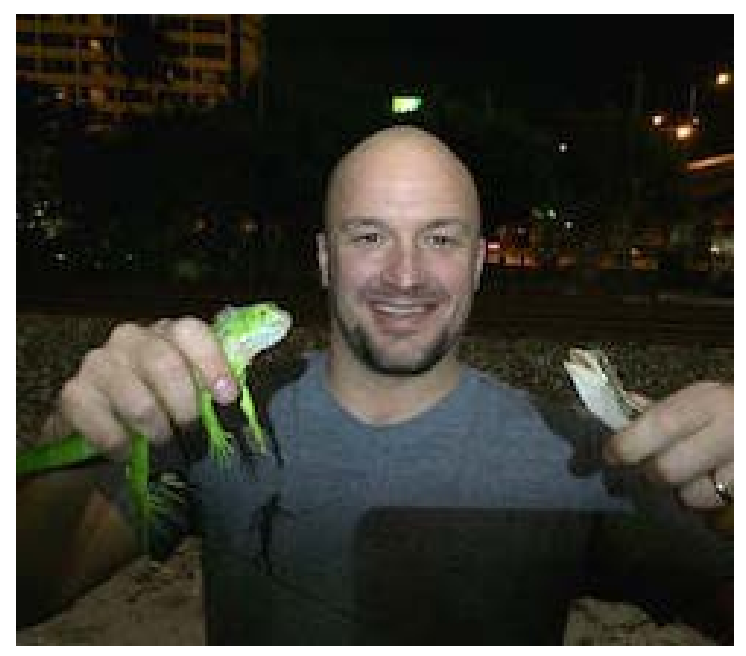

523 Matthew E. Gifford is an ecological and evolutionary physiologist and Assistant Professor in the

524 Department of Biology at theUniversity of Central Arkansas in Conway, Arkansas. Matt

525 received his B.S. in Biology from Avila College, his M.S. in Biology from the University of 
526 Texas at Tyler, and his Ph.D. in Ecology, Evolution, and Population Biology from Washington

527 University in St. Louis. Hisprimary research interests include the ecological andevolutionary 528 physiology of vertebrate ectotherms.

529 